\title{
Failure prediction of axi-symmetric cup in deep drawing and expansion processes
}

https://doi.org/10.1515/eng-2018-0045

Received Nov 15, 2017; accepted Mar 08, 2018

\begin{abstract}
Presented work deals with the prediction of the forming limit of food can obtained with deep drawing, reverse drawing and expansion operations. Two commonly used materials of TH330 steel and AA5352 aluminium alloy for packaging can production were studied. Finite element simulation (FEM) is an essential tool in the packaging industry to prevent different sheet metal forming difficulties such as failure under complex nonlinear strain paths and plastic anisotropic earing. In order to characterise the material plastic properties and to specify failure criteria, the uniaxial tensile, hydraulic bulge test, as well as the routines for obtaining forming limit curves were carried out. The input material data required for various material models are also described. Utilisation of advanced material models in numerical simulation require a large number of input data. Prediction of failure location in drawing and expansion of axi-symmetric cups were estimated for each material. The FEM results were verified by real experiments.
\end{abstract}

Keywords: Deep drawing, redrawing, expansion, failure prediction, crack location

\section{Introduction}

The deep drawing process is one of the most used progressive forming methods with a wide range of applications in different fields such as packaging, automotive and aerospace industries. In this process, a sheet metal is

\footnotetext{
*Corresponding Author: Ján Slota: Faculty of Mechanical Engineering, Technical University of Košice, Mäsiarska 74, 04001 Košice, Slovakia; Email: jan.slota@tuke.sk; Tel.: +421 556023545 Marek Šiser: Faculty of Mechanical Engineering, Technical University of Košice, Mäsiarska 74, 04001 Košice, Slovakia; Email: marek.siser@tuke.sk; Tel.: +421556023519

Ivan Gajdoš: Faculty of Mechanical Engineering, Technical University of Košice, Mäsiarska 74, 04001 Košice, Slovakia; Email: ivan.gajdos@tuke.sk; Tel.: +421556023518
}

transformed into a hollow part using forming tools whose geometry is consistent with the shape of the part. Several process variables influence the success of a deep drawing process. These include the tool geometry, the blankholding force, the friction conditions, mechanical properties of the blank and others.

In recent years, many research works have been conducted to study the influence of process variables on forming process using finite element simulations.

Numerical simulation of deep drawing axi-symmetric cups provides significant information for processors in the packaging industry. Thanks to FEM simulation, we can predict many different errors that greatly affect the cups production. These errors include extreme thinning, earing, which is affected by plastic anisotropy, wrinkling, binding, cosmetic defects on cups and cracks or fractures started from various combinations of stress states on the cup, such as, for example, during deep-drawing and cup expansion.

Based on the background knowledge and experiences [1-4], it is important to select a suitable material model to predict the material behaviour during plastic deformation to achieve adequate simulation results. One of the most significant factors that are included in the material model is the hardening curve, the yield function, and the forming-limit curve. In order to achieve a better correlation of prediction with experimental results, several works have focused on improving the quality of constitutive models. Authors [5-7] focused on the effect of the yield function, in the works $[8,9]$ the influence of the hardening curve was examined. A large number of research works [10-13] deal with predicting failures, where forming limit diagram (FLD) is used. In many cases, the authors deal only with deep drawing processes. However, there is relatively little research on combined processes such as deep drawing, reverse drawing and expansion. Our study aims at predicting sheet behaviour after deep drawing, reverse drawing and expansion using FEM simulation. The main objective of this study was focused on predicting the failure point after the expansion operation. 
Table 1: Basic mechanical properties of studied materials

\begin{tabular}{ccccccc}
\hline Material & Direction & $\begin{array}{c}\text { Yield } \\
\text { Strength } \\
{[\mathrm{MPa}]}\end{array}$ & $\begin{array}{c}\text { Tensile } \\
\text { Strength } \\
{[\mathrm{MPa}]}\end{array}$ & \multicolumn{2}{c}{ Elongation [\%] } & $\begin{array}{c}\text { Normal } \\
\text { anisotropy }\end{array}$ \\
\hline AA5352 & $0^{\circ}$ & 197.59 & 239.29 & 8.219 & 11.230 & 0.535 \\
& $45^{\circ}$ & 193.94 & 231.54 & 9.580 & 13.090 & 1.105 \\
& $90^{\circ}$ & 198.74 & 239.04 & 11.032 & 16.110 & 2.270 \\
\hline TH330 & $0^{\circ}$ & 258.87 & 366.87 & 15.881 & 29.042 & 1.449 \\
& $45^{\circ}$ & 255.25 & 371.02 & 15.665 & 29.505 & 1.266 \\
& $90^{\circ}$ & 249.42 & 367.08 & 15.771 & 29.347 & 1.510 \\
\hline
\end{tabular}

Table 2: Material properties obtained from hydraulic bulge test and Krupkowski hardening curve

\begin{tabular}{ccccccc}
\hline Material & $\begin{array}{c}\text { Thickness }(\mathrm{t}) \\
{[\mathrm{mm}]}\end{array}$ & \multicolumn{2}{c}{$\begin{array}{c}\text { Hydraulic } \\
\text { bulge test }\end{array}$} & \multicolumn{3}{c}{$\begin{array}{c}\text { Krupkowski model } \\
\mathbf{\sigma}=\mathbf{K}\left(\boldsymbol{\varepsilon}_{0}+\boldsymbol{\varepsilon}_{p}\right)^{n}\end{array}$} \\
\cline { 3 - 7 } & & $\begin{array}{c}\mathbf{\sigma}_{\boldsymbol{b}} \\
{[\mathrm{MPa}]}\end{array}$ & $\begin{array}{c}\boldsymbol{\varepsilon}_{\boldsymbol{t}} \\
{[-]}\end{array}$ & $\begin{array}{c}\mathbf{K} \\
{[\mathrm{MPa}]}\end{array}$ & $\boldsymbol{\varepsilon}_{\mathbf{0}}$ & $\mathbf{n}$ \\
\hline AA5352 & 0.279 & 304.24 & 0.1200 & 362.7 & 0.0161 & 0.1535 \\
TH330 & 0.270 & 579.86 & 0.4642 & 575.8 & 0.0045 & 0.1578 \\
\hline
\end{tabular}

\section{Methodology}

Experiments with two different materials were carried out. Medium strength steel grade TH330 is double reduced and tin coated sheet, specifically intended for round or rectangular cans. It is the most common material used in can industry [14]. The alternative is aluminium alloy AA5352, used for packaging production processes, but also in automotive and electrotechnical industry. This aluminium alloy has good formability and high hardening rate. Due to the presence of magnesium, it is susceptible to oxidation and has to be heat treated [15]. In order to determine input data required for FEM simulation, basic mechanical and technological tests were carried out. In the present study, the material properties were characterized by both tensile and hydraulic bulge tests. The tensile test was carried out according to standard ISO 6892-1:2016. From the test, basic mechanical properties as yield point, ultimate tensile stress, the strain-hardening exponent, uniform elongation, Lankford's coefficients and others material parameters were obtained. The mechanical properties obtained from the tensile test are shown in Table 1.

Thin sheet metal usually splits at a strain of approximately $10 \%$ for aluminium and $20 \%$ for steel in a uniaxial tensile test. In order to obtain the material data at higher strains, hydraulic bulge test is commonly used to extend the tensile test data. The use of this test contributes to reducing discrepancies on data extrapolation of hardening curves too. Scheme of the hydraulic bulge test is shown in Figure 1. Following equations were used to calculate the equivalent stress:

$$
\begin{gathered}
\sigma_{b}=\frac{p R}{2 t} \\
t=t_{0}{ }^{\star} \exp \left(-\varepsilon_{t}\right)
\end{gathered}
$$

where $\sigma_{b}$ is effective stress [MPa], $p$ is hydraulic pressure [MPa], $R$ is the radius of curvature $[\mathrm{mm}], \varepsilon_{t}$ is current thickness strain, $t$ and $t_{0}$ are actual and initial thicknesses $[\mathrm{mm}]$.

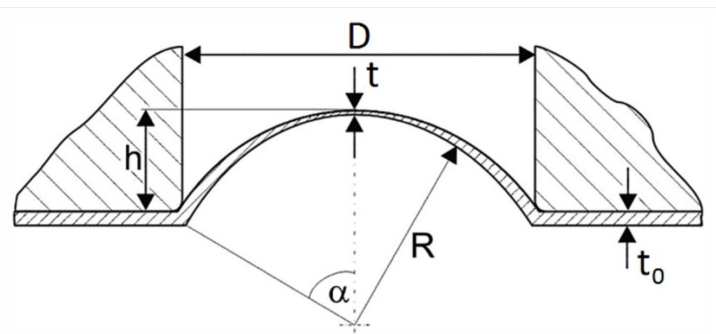

Figure 1: Scheme of the hydraulic bulge test

Using values from hydraulic bulge test the strainhardening curve can be established. The parameters for determination of hardening curve and results of hydraulic bulge test are shown in Table 2. 




Figure 2: Device for estimating of FLC by Nakajima test

In sheet metal forming, the FLD is commonly used to predict material failure in forming operations. The failure of sheet material can be induced by strain paths ranging from uniaxial tension to plane strain and biaxial tensile loading (different ratios between major and minor strains). Forming limit curve (FLC) represents the major and the minor strains in the plane of a sheet and corresponds to the maximum admissible local strains achievable just before the occurrence of visible defects in the sheet metal like fracture or necking.

FLC's were determined according to the ISO 120042:2008 for both sheet materials. The universal sheet metal testing machine Erichsen 145-60 was used for performing the tests. Experimental samples with different radii were cut and Nakajima test with punch diameter of $100 \mathrm{~mm}$ was applied. The machine can provide controllable slide velocity, and punch speed was set to $1.5 \mathrm{~mm} / \mathrm{s}$. The test was measured by 3D optical system Aramis M5. The experimental device is shown in Figure 2.

The experiment consisted of three operations. Cup was formed in a two-stage process of drawing and reverse redrawing using a combination tool (Figure 3), which occur sequentially during a single stroke of the drawing operation punch. The formed cup was subsequently subjected to die expansion operation. The diameter of the blank was $\emptyset 162.96$ for both materials. Die extension operation was realized in the separate tool (Figure 4). Inner die diameter in deep drawing operation was $\emptyset 116.84 \mathrm{~mm}$. Cup without flange with an average height of $27.5 \mathrm{~mm}$ was drawn. After cup was fully drawn followed redrawing operation. As it is shown in Figure 3, in the combination tool the punch from the first operation was used as die in the second operation. Inner die diameter was $\emptyset 87.85 \mathrm{~mm}$ and cup was drawn without failure with approximately $52.5 \mathrm{~mm}$ of height.

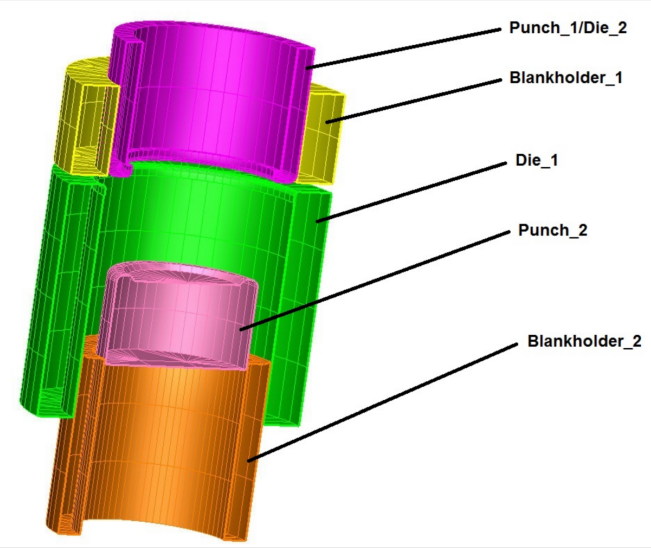

Figure 3: Combination tool for deep drawing and redrawing operations

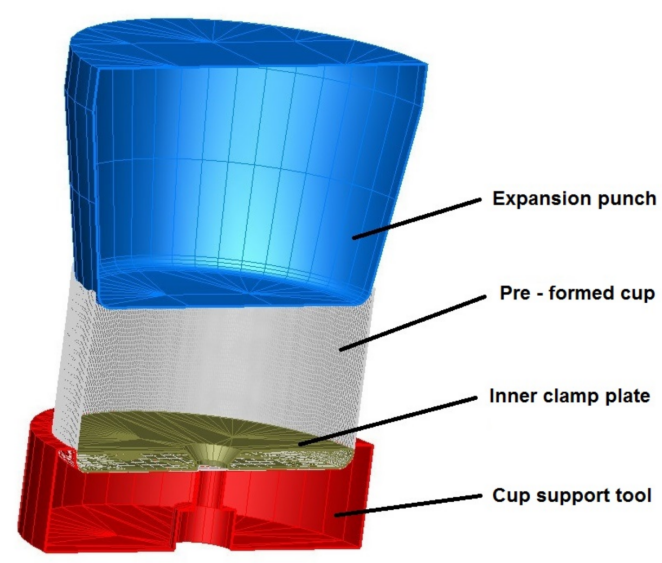

Figure 4: Experimental tool for expansion operation

After drawing operations, the die expansion operation was performed. From practical knowledge we know, that force required to expand cup up to failure will cause the material flow to the bottom of the cup. This cause wrinkling in the cup bottom and reduce cup height. To avoid this, the bottom of the cup was clamped by inner clamp plate attached by a bolt to cup support tool. The preformed cup was placed between inner clamp plate and cup support tool as shown in Figure 4. In the centre of the bottom of cup is placed hole with $\emptyset 9 \mathrm{~mm}$ diameter. Clamp- 
Table 3: Parameters defined in Pam-Stamp 2G software

\begin{tabular}{lcccc}
\hline & Units & Deep drawing & Redrawing & Expansion \\
\hline Drawing speed & {$[\mathrm{mm} / \mathrm{min}]$} & 400 & 400 & 200 \\
Friction coefficient & {$[-]$} & 0.05 & 0.05 & 0.05 \\
Holding force & {$[\mathrm{kN}]$} & 21.1 & 16.6 & - \\
\hline
\end{tabular}

Table 4: Parameters defined in FEM software

\begin{tabular}{lccc}
\hline Parameter & Value & Parameter & Value \\
\hline Mesh type & Quadrilateral & Level of refinement & 5 \\
Element type & Shell & Hardening curve & Krupkowski \\
Friction coefficient & 0.05 & Hardening Rule & Isotropic \\
Yield function (TH330) & Hill48 & Yield function (AA5352) & Barlat2000 \\
Number of integration points & 5 & Failure criteria & Strain-based FLD \\
\hline
\end{tabular}

ing plate was screwed to cup support tool (Figure 4). Bleed at punch prevents accumulation of air. The same clamp arrangement is used for both materials - steel and aluminium alloy. Some process parameters defined in FEM code are shown in Table 3.

FEM software with the explicit time-integration scheme was used. Parameters defined in numerical simulation are shown in Table 4.

The tools geometry together with material input data were imported into FEM software. Krupkowski hardening curve was used for both materials because it shows the best correlation with experimental curves. For each material, different yield function was used. Hill48 yield function best describes the behaviour of the conventional steel materials during plastic deformation. This material law is most frequently used for steel materials and therefore been used in this case for steel tinplate TH330. However, this yield function is not suitable for aluminium alloys [16]. Therefore, more sophisticated yield function e.g. Barlat2000 is needed [16]. This law requires determining both, the exponent $m$ and eight parameters used in the model. Exponent $m$ is defined on the basis crystalline structure of the material. For metals with so-called BCC unit cell like steel is $m=6$, while for FCC metals like aluminium alloys is exponent $m=8$. These eight coefficients are required for this function and they have been gained numerically, based on the mechanical tests referred to Table 5 [17]. For anisotropic yield models, the biaxial $r$ value $(r b)$ is required and obtained from disk compression tests.

Krupkowski hardening curve is defined as [17]:

$$
\sigma=K^{\star}\left(\varepsilon_{p}+\varepsilon_{o}\right)^{n}
$$

where $\varepsilon_{p}$ is plastic strain [-], $\varepsilon_{o}$ is offset strain [-], $n$ is strain hardening exponent [-] a $K$ is material constant [MPa].

For plane stress conditions Hill48 yield function may be written as [16]:

$$
\sigma_{K}^{2}=\sigma_{1}^{2}-\left(\frac{2 \star r_{0}}{1+r_{0}}\right) \star \sigma_{1} \star \sigma_{2}+\frac{r_{0}}{r_{90}} \star\left(\frac{1+r_{90}}{1+r_{0}}\right) \star \sigma_{2}^{2}
$$

where $\sigma_{K}$ is yield stress [MPa], $\sigma_{1}$ is major principal stress [MPa], $\sigma_{2}$ is minor principal stress [MPa] and $r_{0}, r_{45}, r_{90}$ are Lankford's coefficients [-].

Barlat2000 (Yield2000 $2^{\text {nd }}$ ) yield function can be written as [18]:

$$
\begin{gathered}
\phi^{\prime}=\left|S_{1}^{\prime}-S_{2}^{\prime}\right|^{M} ;{ }^{\prime \prime}=\left|2 S_{2}^{\prime \prime}+S_{1}^{\prime \prime}\right|^{M}+\left|2 S_{1}^{\prime \prime}+S_{2}^{\prime \prime}\right|^{M} \\
\phi=\left|S_{1}^{\prime}-S_{2}^{\prime}\right|^{M}+\left|2 S_{2}^{\prime \prime}+S_{1}^{\prime \prime}\right|^{M}+\left|2 S_{1}^{\prime \prime}+S_{2}^{\prime \prime}\right|^{M}=2 \sigma_{y}^{M}
\end{gathered}
$$

The $S_{i}^{\prime}$ and $S_{i}^{\prime \prime}$ are the principal values of stress tensors $S^{\prime}$ and $S^{\prime \prime}$, which can be expressed by:

$$
\tilde{S}_{1,2}=\frac{1}{2}\left(\tilde{s}_{x x}+\tilde{s}_{y y} \pm \sqrt{\left(\tilde{s}_{x x}-\tilde{s}_{y y}\right)^{2}+4 \tilde{S}_{x y}^{2}}\right)
$$

The $S_{i j}^{\prime}$ and $S_{i j}^{\prime \prime}$ are the linear functions of the stress deviators.

$$
\begin{aligned}
& \left(\begin{array}{l}
s_{x x}^{\prime} \\
s_{y y}^{\prime} \\
s_{x y}^{\prime}
\end{array}\right)=\left[\begin{array}{ccc}
L_{11}^{\prime} & L_{12}^{\prime} & 0 \\
L_{21}^{\prime} & L_{22}^{\prime} & 0 \\
0 & 0 & L_{66}^{\prime}
\end{array}\right]\left(\begin{array}{l}
s_{x x} \\
s_{y y} \\
s_{x y}
\end{array}\right) \\
& \left(\begin{array}{c}
s_{x x}^{\prime \prime} \\
s_{y y}^{\prime \prime} \\
s_{x y}^{\prime \prime}
\end{array}\right)=\left[\begin{array}{ccc}
L_{11}^{\prime \prime} & L_{12}^{\prime \prime} & 0 \\
L_{21}^{\prime \prime} & L_{22}^{\prime \prime} & 0 \\
0 & 0 & L_{66}^{\prime \prime}
\end{array}\right]\left(\begin{array}{l}
s_{x x} \\
s_{y y} \\
s_{x y}
\end{array}\right)
\end{aligned}
$$


Table 5: Summary of experimental data used in calibration of the Yld2000-2d model

\begin{tabular}{lcc}
\hline Test & Flow stress ratio & Normal anisotropy - r \\
\hline Uniaxial tensile test $\left(7 x @ 0^{\circ}, 15^{\circ}, 30^{\circ}, 45^{\circ}, 60^{\circ}, 75^{\circ}, 90^{\circ}\right)$ & $\checkmark$ & $\checkmark$ \\
Disk compression & - & $\checkmark$ \\
Hydraulic bulge test & $\checkmark$ & - \\
\hline
\end{tabular}

$$
\begin{gathered}
\left(\begin{array}{l}
L_{11}^{\prime} \\
L_{12}^{\prime} \\
L_{21}^{\prime} \\
L_{22}^{\prime} \\
L_{66}^{\prime}
\end{array}\right)=\left[\begin{array}{ccc}
2 / 3 & 0 & 0 \\
-1 / 3 & 0 & 0 \\
0 & -1 / 3 & 0 \\
0 & 2 / 3 & 0 \\
0 & 0 & 1
\end{array}\right]\left(\begin{array}{l}
\alpha_{1} \\
\alpha_{2} \\
\alpha_{7}
\end{array}\right) \\
\left(\begin{array}{l}
L_{11}^{\prime \prime} \\
L_{12}^{\prime \prime} \\
L_{21}^{\prime \prime} \\
L_{22}^{\prime \prime} \\
L_{66}^{\prime \prime}
\end{array}\right)=\left[\begin{array}{ccccc}
-2 & 2 & 8 & -2 & 0 \\
1 & -4 & -4 & 4 & 0 \\
4 & -4 & -4 & 4 & 0 \\
-2 & 8 & 2 & -2 & 0 \\
0 & 0 & 0 & 0 & 9
\end{array}\right]\left(\begin{array}{l}
\alpha_{3} \\
\alpha_{4} \\
\alpha_{5} \\
\alpha_{6} \\
\alpha_{8}
\end{array}\right)
\end{gathered}
$$

The coefficients $L_{i j}^{\prime}$ and $L_{i j}^{\prime \prime}$ are described by relationships of a set of eight coefficients $\alpha_{k}$ as shown in (10) and (11). The coefficients $\alpha_{1}-\alpha_{8}$ are reduced to one coefficient if an isotropic case is considered.

Even if the aim of this section is to failure prediction during expansion operation, other important values were analysed too. Overall, there are four parameters evaluated in this work:

(i) Ear profile after deep drawing,

(ii) Wall thickness after deep drawing in $25 \mathrm{~mm}$ and 45 $\mathrm{mm}$ distance from cup bottom,

(iii) Punch force,

(iv) The position of crack.

\section{Results and discussion}

Since we used anisotropic models (anisotropy in $0^{\circ}, 45^{\circ}$ and $90^{\circ}$ according to rolling direction) results will be same in every quadrant (every $90^{\circ}$ ) of the specimen. For this reason, all compared results will be only in the first quadrant (from $0^{\circ}$ to $90^{\circ}$ ). As the first, the earing profile after redrawing cycle was examined. Cup height was measured around the whole specimen as shown in Figure 5. The biggest impact in ear creation has material anisotropy. In the directions where the coefficient of normal anisotropy was higher, ear occurs on cups.

The following data was measured in experimental cups:

(i) Steel cups:

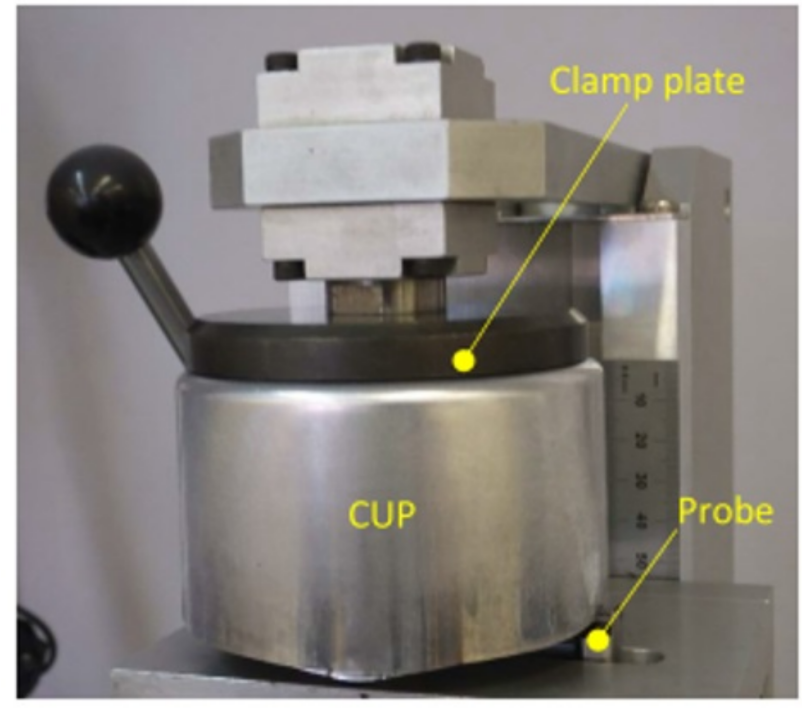

Figure 5: Ear measurement [19]



Figure 6: Ear creation on aluminium cup [19]

- Creation of 4 ears in $0^{\circ}, 90^{\circ}, 180^{\circ}$ and $270^{\circ}$ direction

- Average cup height was $52.61 \mathrm{~mm}$

- Amplitude (max-min) was 1.14 mm.

(ii) Aluminium alloy cups: 

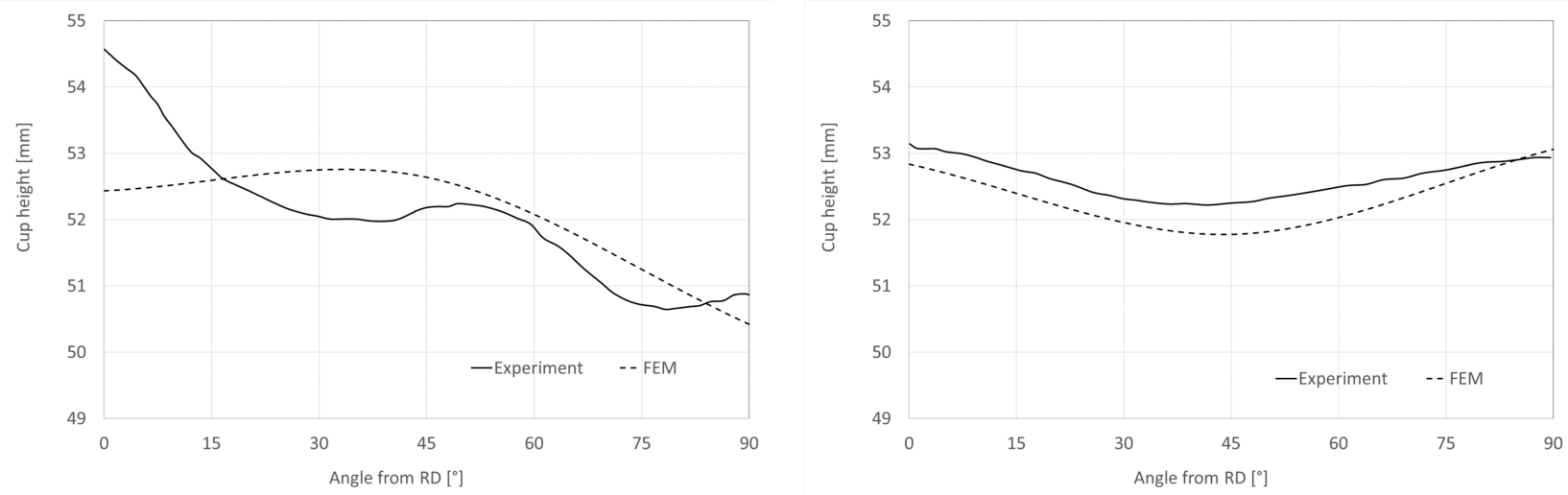

Figure 7: Ear profile of the cup from aluminium alloy AA5352 (left) and steel sheet TH330 (right)
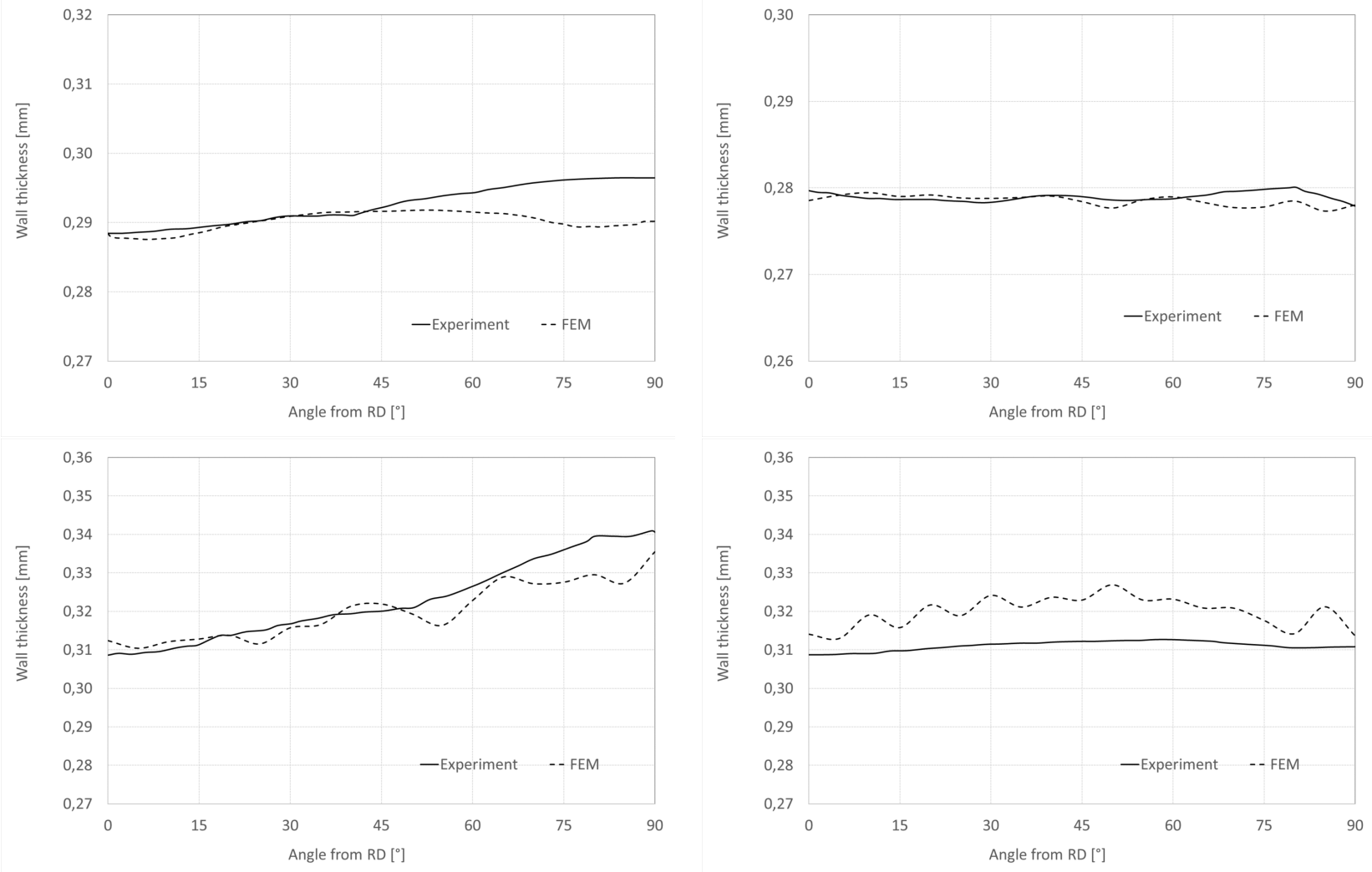

Figure 8: Wall thickness of AA 5352 (left) and TH330 steel (right) in $25 \mathrm{~mm}$ (top) and $45 \mathrm{~mm}$ (bottom) from cup base

- Creation of 8 ears in $0^{\circ}, 45^{\circ}, 90^{\circ}, 135^{\circ}, 180^{\circ}$, $225^{\circ}, 270^{\circ}$ and $315^{\circ}$ direction

- Average cup height was $52.05 \mathrm{~mm}$

- Amplitude (max-min) was $4.13 \mathrm{~mm}$

- As a result of blankholder load acting in the directions $0^{\circ}$ and $180^{\circ}$ was material highly thinned, and secondary ears were created (Figure 6).
Results of the experiment and FEM simulation are compared in the Figure 7 - 9. The cup heights of studied materials are shown in Figure 7. At the left side is the comparison of aluminium alloy experimental cup height with FEM simulation. The main difference is in $0^{\circ}$ direction. That is due to the above-mentioned blankholder force applied in the rolling direction. In the directions $0^{\circ}$ and $180^{\circ}$ regarding to rolling direction was material highly thinned and secondary ears were created. This phenomenon is closely linked to the so-called ironing effect, which is an 

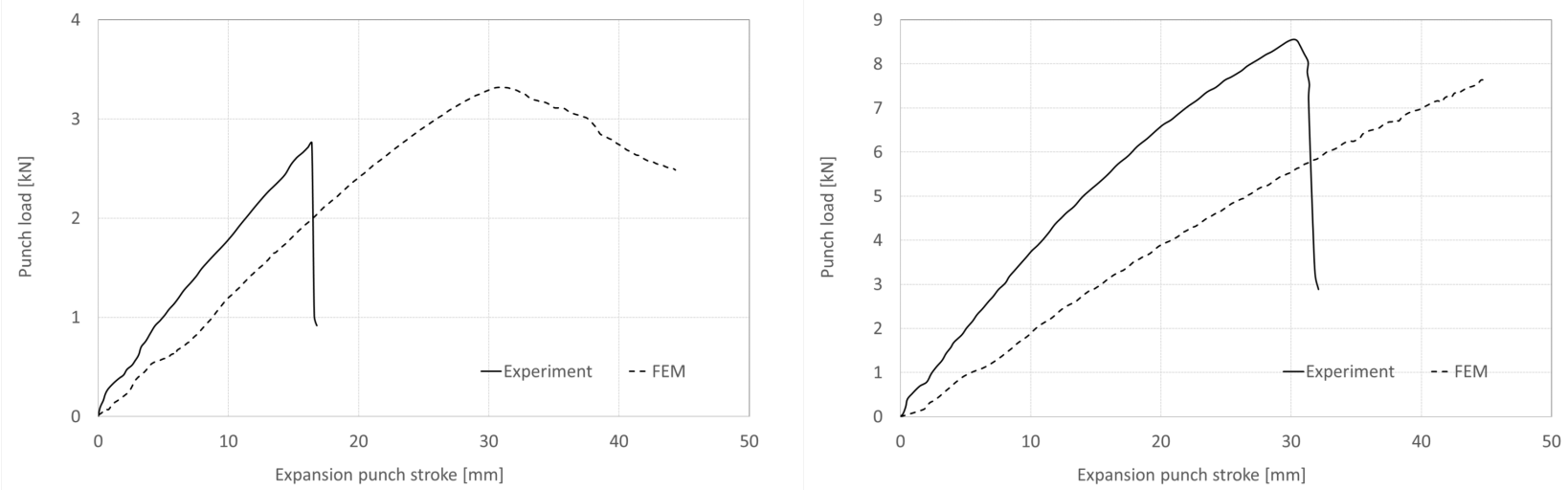

Figure 9: Punch force during expansion operation for AA5352 (left) and TH330 sheets (right)

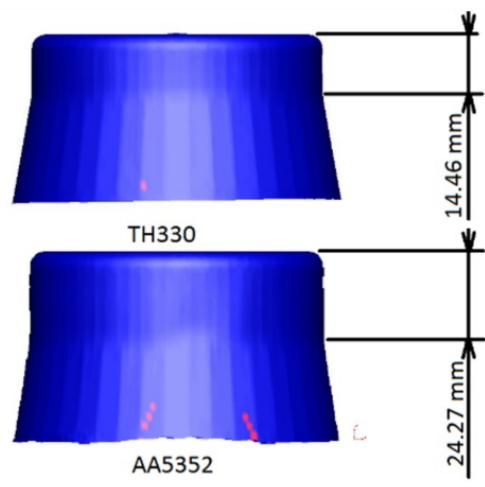

a.)

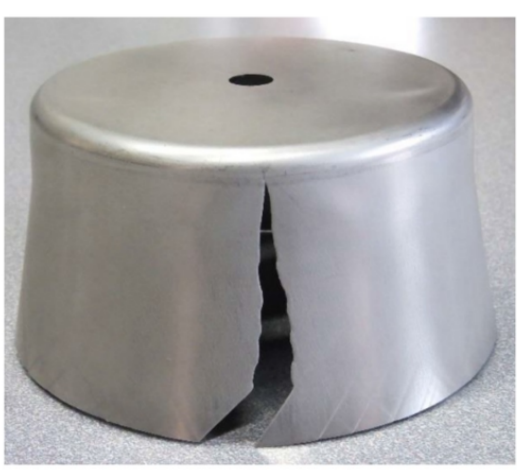

b.)

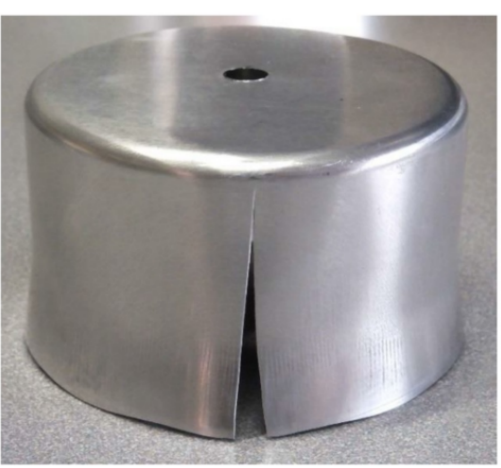

c.)

Figure 10: Expansion punch stroke at the moment of failure occurred (a.), drawn cups with failure of TH330 (b.) [19] and AA5352 (c.) [19]

increase in wall thickness (Figure 8). For deep drawing was used the same tool, with the gap between the punch and the die of $0.605 \mathrm{~mm}$ for drawing and $0.63 \mathrm{~mm}$ for redrawing. For material with a higher thickness, which was an aluminium alloy, the effect is more significant. The average cup height of aluminium was $51.81 \mathrm{~mm}$ and steel $52.56 \mathrm{~mm}$. The amplitude for steel was $1.29 \mathrm{~mm}$ and for aluminium $2.22 \mathrm{~mm}$.

Another compared parameter was wall thickness after redrawing cycle in $25 \mathrm{~mm}$ and $45 \mathrm{~mm}$ distance from the cup base. Measurement of experimental samples was carried out on the whole circumference at a distance of $30^{\circ}$. Results of numerical simulation were compared with experimental results and are shown in Figure 8. Wall thickness $25 \mathrm{~mm}$ from cup base is same for both materials and shown a little deviations.

Next, the punch force during the expansion operation was evaluated. Experimental results are compared with numerical simulation in Figure 9. On the right are results for steel TH330 and on the left for aluminium alloy AA5352.
The failure occurred during the last operation. The distance from the base to the expansion punch at the moment of crack formation for each material was measured (Figure 10). In aluminium alloy, the crack appeared when the punch stroke reached $25.55 \mathrm{~mm}$, corresponding to distance from expansion punch to the bottom of cup $24.27 \mathrm{~mm}$. As regards the steel TH330, the crack appeared when punch stroke reached $35.33 \mathrm{~mm}$, which is $14.46 \mathrm{~mm}$ from the base. When the failure occurs, cup height reached $49.79 \mathrm{~mm}$ for TH330 and $49.82 \mathrm{~mm}$ for AA5352 material. Figure 11 shows the position of failures.

As shown in Figure 11, numerical results more accurately predicted the position of the crack at the AA5352 aluminium alloy as for TH330 steel. This may result from the yield function. Aluminium alloys require a more sophisticated description of yield function such as Barlat2000. This anisotropic model gives a more precise prediction of material behaviour. For most conventional steels, the Hill48 yield law is sufficient, but for high-strength steels or aluminium alloys, this model is not appropriate. To 


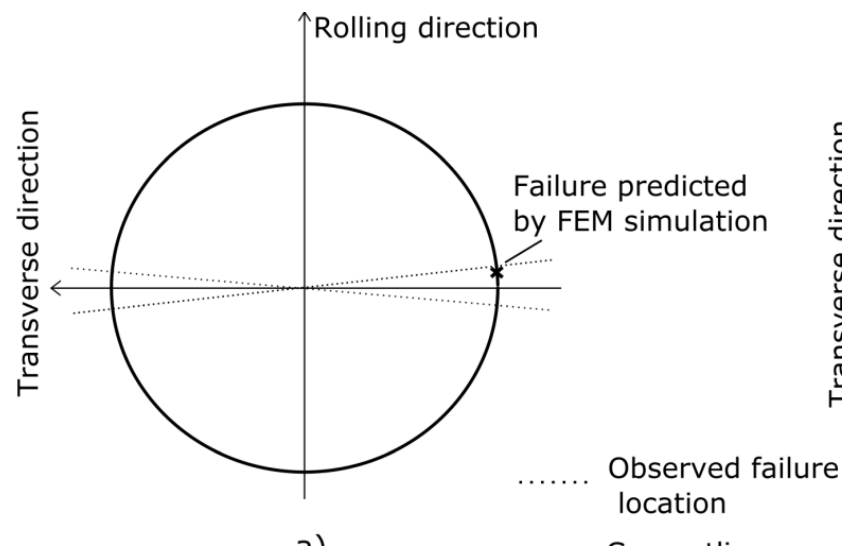

a)



b)

Figure 11: Failure position for AA5352 (a) and TH330 (b) sheets

describe material behaviour with satisfactory accuracy, Hill90, BBC, Vegter or other more sophisticated models should be used.

\section{Conclusions}

Simulations of the sheet metal parts forming processes using FEM are performed in the early design phases. Many commercial FE programs are today capable of reliably predicting possible crack and tear formation, wrinkle, earing from plastic anisotropy and many different sheet metal defects and instabilities that significantly affect the efficient production of these parts. Approximation of the simulation model is satisfactory to achieve good forming simulation results. However, for a more accurate calculation, the material model used and the hardening rule for describing sheet metal behaviour have great influence. This study has the main objective of predicting the failure point after deep-drawing, reverse redrawing and expansion operations. Two commonly used materials of TH330 steel and AA5352 aluminium alloy for packaging can production were studied. For each sheet metal, the material model for FEM analysis was created. Results of numerical simulation were compared with experimental results.

Prediction of earing after the reverse redrawing operation due to the plastic anisotropy of the material showed good correlation with experimental results. For TH330, the experimentally measured average cup height was 52.61 $\mathrm{mm}$ and the difference in max and min height was $1.14 \mathrm{~mm}$, with numerical simulation predicting a difference in max and min height of $1.3 \mathrm{~mm}$ and an average cup height of $52.27 \mathrm{~mm}$. For the aluminium alloy, an average cup height was $52.05 \mathrm{~mm}$ and a difference in max and min height was
$4.13 \mathrm{~mm}$, which in numerical simulation corresponds to an average cup height was $50.76 \mathrm{~mm}$ and a difference in max and min height was $2.22 \mathrm{~mm}$. As a result, the selected material model for TH330 steel was more accurate in this case.

Experimentally measured values of the wall thickness correlated with the FEM simulation results more at a distance of $25 \mathrm{~mm}$ from the cup bottom than $45 \mathrm{~mm}$ from the bottom. This applied to both investigated materials. However, in the case of aluminium alloys, deviations were not so pronounced. The more sophisticated material model thus predicted more accurately the thickness of the cup wall. The failure position after the expansion operation for AA5352 material was more accurately predicted. Our findings can be useful for achieving a more accurate prediction of the forming processes.

Acknowledgement: This paper is the result of the implementation of projects VEGA 1/0441/17 and APVV-14-0834.

\section{References}

[1] Šiser M., Slota J., Material Model of AW 5754 H11 Al Alloy for Numerical Simulation of Deep Drawing Process, Acta Mechanica Slovaca, 2016, 20 no.2, 32-40

[2] Slota J., Šiser M., Advanced material models for stamping of AW 5754 aluminum alloy, Strength of Materials, 2016, 48 no. 4, 487494

[3] Sumikawa S., Ishiwatari A., Hiramoto J., Urabe T., Improvement of springback prediction accuracy using material model considering elastoplastic anisotropy and Bauschinger effect, Journal of Materials Processing Technology, 2016, 230, 1-7

[4] Mulder J., Vegter H., et. al., Accurate determination of flow curves using the bulge test with optical measuring systems, Journal of Materials Processing Technology, 2015, 226, 169-187 
[5] Williams B. W., Boyle K.P., Characterization of anisotropic yield surfaces for titanium sheet using hydrostatic bulging with elliptical dies, International Journal of Mechanical Sciences, 2016, 114, 315-329

[6] Reis L.C., Oliveira M.C., Santos A.D., Fernandes J.V., On the determination of the work hardening curve using the bulge test, International Journal of Mechanical Sciences, 2016, 105, 158-181

[7] Chen K., Scales M., Kyriakides S., Corona E., Effects of anisotropy on material hardening and burst in the bulge test, International Journal of Solids and Structures, 2016, 82, 70-84

[8] Liu K., Lang L., Cai G., Yang X., Guo C., Liu B., A novel approach to determine plastic hardening curves of AA7075 sheet utilizing hydraulic bulging test at elevated temperature, International Journal of Mechanical Sciences, 2015, 100, 328-338

[9] Tian H., Kang D., A study on determining hardening curve for sheet metal, International Journal of Machine Tools \& Manufacture, 2003, 43, 1253-1257

[10] Esmaeilpour R., et. al., Comparison of 3D yield functions for finite element simulation of single point incremental forming (SPIF) of aluminum 7075, International Journal of Mechanical Sciences, 2017, 133, 544-554

[11] Cardoso R.P.R., Adetoro O.B., A generalisation of the Hill's quadratic yield function for planar plastic anisotropy to consider loading direction, International Journal of Mechanical Sciences, 2017, 128-129, 253-268

[12] Banabic, D., et al., FLD theoretical model using a new anisotropic yield criterion, Materials Processing Technology, 2004, 273-281.
[13] Cao J., Li F., Ma X., Sun Z., A modified elliptical fracture criterion to predict fracture forming limit diagrams for sheet metals, Journal of Materials Processing Tech, 2017, 252, 116-127

[14] Steel for packing: Product catalogue. Arcelor Mittal, Flat Carbon Europe, http://packaging.arcelormittal.com/repository2/ Unassigned/ArcelorMittal\%20Packaging\%20\%20product $\%$ 20catalogue.pdf

[15] Jin, H., Wagstaff B., Gallerneault, M., Lloyd, D. J., Microstructure and Deformation Properties of AA5352/Al-6\%Mg Sheet Produced by the Direct Chill Casting Fusion Process, Proceedings of the 12th International Conference on Aluminium Alloys, 2010, 2186-2191

[16] Mulidrán, P.; Šiser, M.; Slota, J.; Spišák, E.; Sleziak, T., Numerical Prediction of Forming Car Body Parts with Emphasis on Springback, Metals, Vol. 8 (6), 435, 2018, 1-15, ISSN 2075-4701.

[17] Slota J., Numerical simulation of sheet metal forming processes, (in Slovak) 1st ed., Technical University, Košice, 2016

[18] Panich, S., Barlat, F., Uthaisangsuk, V. et. al.: Experimental and theoretical formability analysis using strain and stress based forming limit diagram for advanced high strength steels, Materials \& Design, Vol 51, 2013, 756-766

[19] Watson M., Dick R., Huang Y. H., Lockley A., Cardoso R., Santos A., Failure Prediction after Cup Drawing, Reverse Redrawing and Expansion Part, Journal of Physics: Conference Series 734, 2016, 1-85 